\title{
Management of conjunctivitis and other causes of red eye during the COVID-19 pandemic
}

Jane Khan, Heather G Mack

\section{Background \\ Patients with red eyes frequently present to general practitioners (GPs). Although infrequent, some patients with COVID-19 may present with features typical of viral conjunctivitis. SARS-CoV-2 is expressed at a low rate in tears, which may be a source of infection to GPs caring for patients at high risk of COVID-19.}

\section{Objective}

The aims of this article are to outline: 1) ophthalmic complications of SARSCoV-2 infection, 2) triage and management of patients with potential COVID-19 conjunctivitis, and 3) triage and management of patients with red eyes during the current COVID-19 pandemic.

\section{Discussion}

It is important that GPs: 1) have a high index of suspicion that patients with apparently typical viral conjunctivitis may have an uncommon presentation of COVID-19 illness, 2) develop appropriate telephone triage systems to reduce patient consultations, and 3) foster relationships with their ophthalmologist and optometrist colleagues who can provide phone advice, guidance on treatment initiation and definitive care when necessary.
AUSTRALIA is experiencing cases of COVID-19 illness due to the SARS-CoV-2 virus, with recent high levels of community transmission in Victoria (at time of writing, 14 August 2020). Conjunctivitis may be a feature of this illness, with tears containing SARS-CoV-2 virus being a source of potential transmission. General practitioners (GPs) frequently see patients with red eyes and need to be aware of management to initiate while taking necessary precautions to reduce spread to themselves and the community.

\section{SARS-CoV-2 virus detected at a low rate in tears}

In December 2019, SARS-CoV-2 first emerged in Wuhan, China. Symptoms are often mild (80\%), with fever, cough and tiredness. Up to $5 \%$ of patients develop critical disease with respiratory failure or multi-organ dysfunction, ${ }^{1}$ for which the intensive care unit mortality rate is approximately $40 \% .^{2}$ There is no vaccine or specific antiviral treatment available, and treatment is limited to supportive care.

Little is known about the ophthalmic features of coronaviruses in general. Animal models show a wide spectrum of disease from conjunctivitis and anterior uveitis, to chorioretinal inflammation and degeneration and optic neuritis. ${ }^{3}$ There are sparse reports of patients infected with other coronaviruses (eg HCoV-NL63) developing conjunctivitis; RNA from SARS-CoV- 1 was detected in tears, ${ }^{4}$ although conjunctivitis was not a common feature of the severe acute respiratory syndrome (SARS) illness.

SARS-CoV-2 is droplet spread (particles $>5 \mu \mathrm{m}$ ). Airborne spread (particles $\leq 5 \mu \mathrm{m}$ ) is controversial, but SARS-CoV-2 is known to be viable following aerosolisation for up to three hours. ${ }^{5}$ SARS-CoV-2 has been detected at a low rate in tears. ${ }^{6}$ In a study of patients with positive reverse transcription polymerase chain reaction (RT-PCR) sputum samples, only one patient with conjunctivitis yielded positive RT-PCR results from a conjunctival swab. However, 58 conjunctival swab samples from 29 patients with positive sputum samples were all negative. Pathogenic SARS-CoV-2 virus has been demonstrated at day 27 in a case of COVID-19 conjunctivitis, seven days after apparent clinical resolution. ${ }^{7}$ In contrast, a further study of 17 cases (one with some ocular redness) showed no PCR or cytopathological effect of SARS-CoV-2 in tear samples even when the nasopharyngeal swabs were positive. ${ }^{8}$ There have been reports that procedures causing aerosolisation from ocular adnexa are high risk for transmission, but these are surgical procedures performed by otolaryngologists using endonasal techniques. Taken together, these data raise the possibility of spread of SARS-CoV-2 via tears and highlight the 
risk of eye examinations as a potentially aerosol-generating procedure with potential risk to healthcare workers.

\section{SARS-CoV-2 conjunctivitis}

It is thought that patients with SARS-CoV-2 may develop eye redness and watering, or conjunctivitis indistinguishable from typical viral conjunctivitis, rarely as the sole presenting complaint. ${ }^{9,10}$ Conjunctivitis is a common presenting problem for GPs, and despite the likely low risk of viral shedding from the conjunctiva, it is important to reduce risk while caring for these patients.

Management recommendations vary regionally depending on COVID-19 case numbers and community transmission. In areas with high community transmission, patients should be triaged prior to attending a general practice clinic. Those at high risk of COVID-19 infection with conjunctivitis should be directed to a COVID-19 testing centre or to a tertiary hospital with an ophthalmology department. Patients considered to be at low risk should be managed by telemedicine consultation if possible.

Patients considered to be at high risk of COVID-19 who arrive unannounced with conjunctivitis should be directed to a COVID-19 testing centre. If examination is necessary, minimum eye examination, while wearing full personal protective equipment (PPE) including protective eyewear, and room disinfection after departure, is recommended. ${ }^{11}$ If follow-up is necessary, this should be done by telemedicine. Patients with significant visual impairment should be referred directly to definitive ophthalmology care to conserve PPE and reduce patient travel in the community. Data are limited, and the risk may be low; however, prudence suggests that during the pandemic GPs consider all patients with conjunctivitis in the setting of an upper respiratory tract infection or typical viral conjunctivitis to have SARS-CoV-2 infection until proven otherwise, and take appropriate precautions wherever possible. The situation is evolving rapidly; these recommendations are likely to change in the future and are clearly time-limited.

\section{Emergency red eye management during the pandemic}

Patients with red eyes will often present to primary care. Approximately $70 \%$ of all patients with acute conjunctivitis present to primary care and urgent care. ${ }^{12}$ Where possible, telehealth should be used during the COVID-19 pandemic to evaluate the severity of red eye symptoms and whether this can be managed conservatively or whether ophthalmological or optometric referral is required. GPs can assess and manage patients as follows.

\section{History}

A good history can help elucidate the cause in many cases and should include evaluation of the age of the patient, duration of symptoms, nature of symptoms, contact lens wear and any associated features. Table 1 gives some examples of the patient profile, symptoms and more common causes of red eyes.

Younger adult patients (aged 20-40 years) are more prone to mild viral conjunctivitis, ${ }^{13}$ trauma, recurrent erosion syndrome, ${ }^{14}$ iritis and contact lens associated ulcers (keratitis). Contact lens wear is a red flag and needs prompt ophthalmic review because of the risk of contact lens-related microbial keratitis, which is an ocular emergency. Older adults (aged $>40$ years) are more prone to dry eye problems and blepharitis, while the elderly (aged $>80$ years) are more prone to bacterial conjunctivitis or acute angle closure glaucoma.

Other features of the history may suggest an underlying cause. Intermittent problems over several months suggests dry eyes and blepharitis. Preceding trauma suggests recurrent erosion syndrome. Contact lens wearers can develop contact lens-related keratitis. Inflammatory arthritis or bowel disease suggests uveitis.

\section{Examination}

The first step in the examination is to test and record the vision; if significantly reduced, serious causes must be considered. Appearance of the cornea, conjunctiva and lids should be noted. Fluorescein staining of the cornea to identify ulceration is recommended. The visual acuity, pattern of fluorescein staining, redness and appearance of the eye can direct the diagnosis. Video apps or smartphone photographs can be useful and included as part of an ophthalmology referral.

Diffuse redness and watering, particularly if unilateral, is more likely to be viral conjunctivitis (Figure 1). Vision is usually good. Severe cases can have inflammatory membranes and subconjunctival haemorrhages (Figure 2). Bilateral redness associated with mucus discharge is more likely to be bacterial conjunctivitis or blepharoconjunctivitis (Figure 3). The clinical features of bacterial and viral conjunctivitis are compared in Table 2. Circumciliary

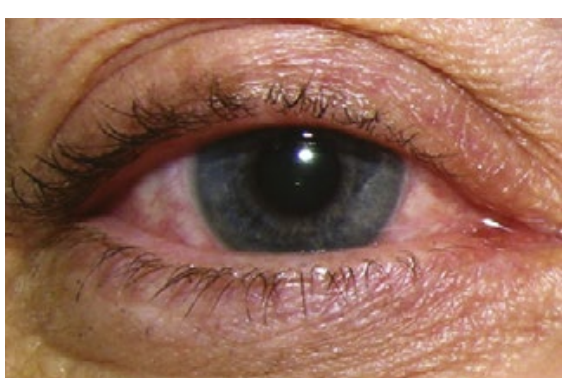

Figure 1. Adenoviral conjunctivitis in a young adult with watery pink eye but clear cornea and good vision

Image courtesy of Emory Eye Center, Emory University School of Medicine, Atlanta, GA.

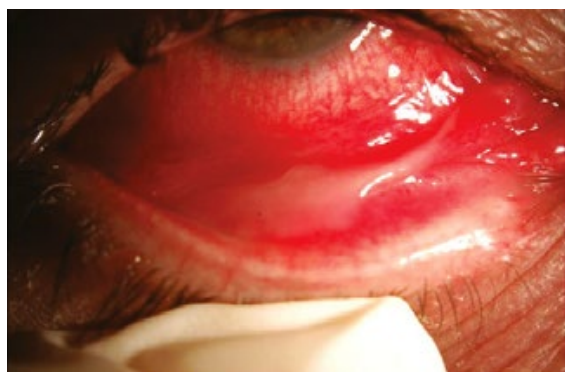

Figure 2. Viral conjunctivitis in a patient with influenza $\mathrm{H} 1 \mathrm{~N} 1$ virus showing injected bulbar and tarsal conjunctiva and pseudomembrane formation. Removing these membranes often leads to small haemorrhages.

Reproduced from Lopez-Prats MJ, Marco ES, Hidalgo-Mora JJ, Garcia-Delpech S, Diaz-Llopis M, Bleeding follicular conjunctivitis due to influenza H1N1 virus, J Ophthalmol 2010;2010:423672, doi: 10.1155/2010/423672, licensed under CC BY 3.0. 
(perilimbal) redness is suggestive of iritis (Figure 4). A painless localised area of injected vessels is typical of episcleritis. Deep boring pain associated with redness throughout the eyeball or a large sector of the sclera may be more indicative of scleritis. Unilateral localised redness with normal vision and no discomfort is typical of subconjunctival haemorrhage.

However, the clinical presentation is often nonspecific. Relying on patient symptoms and type of discharge does not always lead to an accurate diagnosis. ${ }^{13}$ In any patient where there is significant visual loss, involvement of an ophthalmologist is recommended. In areas with significant community transmission and in conditions of shutdown, hospital emergency

\section{Table 1. Common causes of red eye}

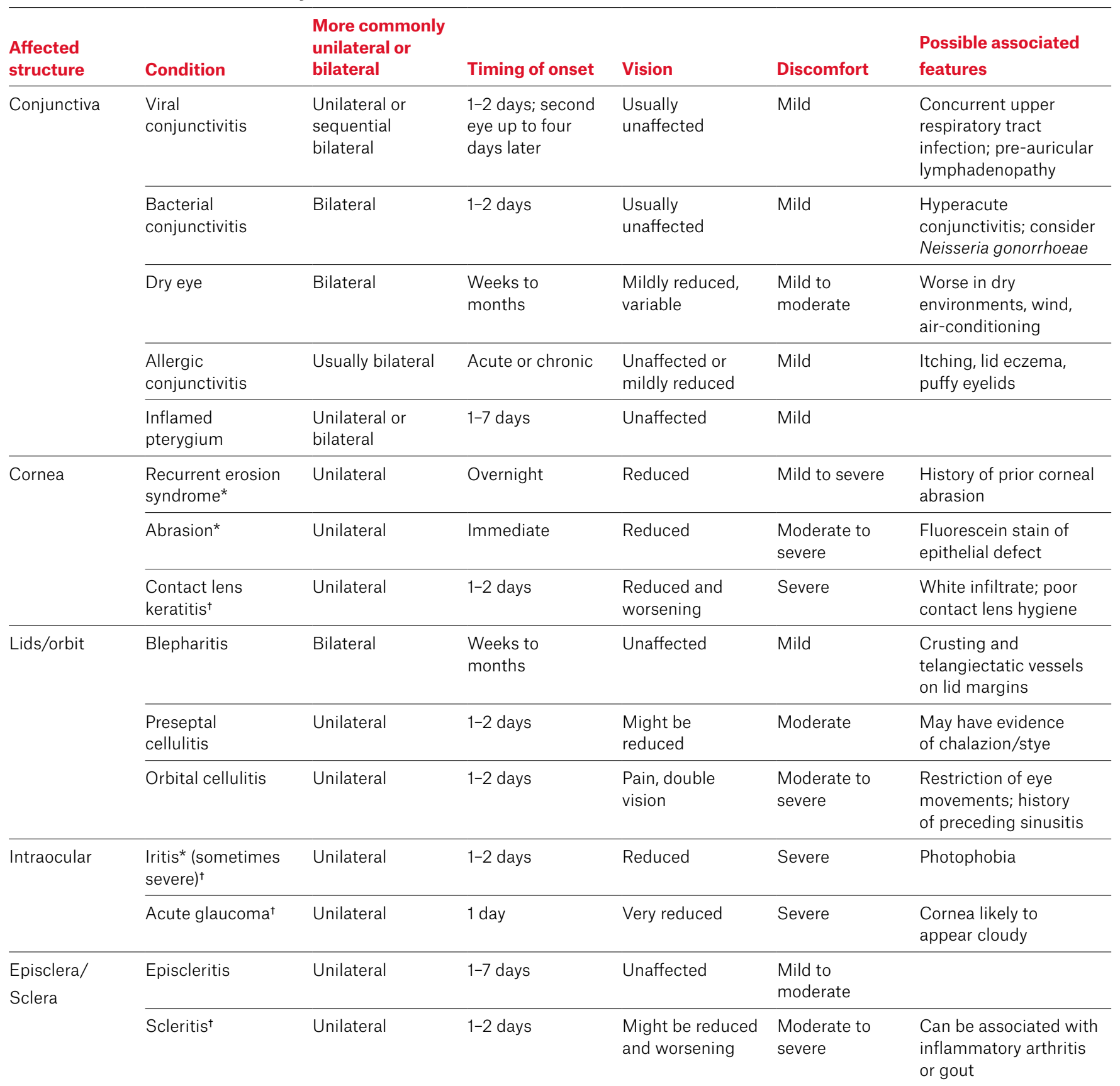


departments and public eye clinics continue to be available and generally open for emergency appointments. If this is not possible during the COVID-19 pandemic, it would be appropriate to obtain an opinion from an ophthalmologist or optometrist by telephone, followed by consultation by telemedicine or in person as appropriate.

\section{Treatment of conjunctivitis}

Most GPs do not have access to slit lamps, and discussion with their usual ophthalmologist or optometrist is recommended. Treatment is based on the suspected cause (Table 3). Treatment for any viral conjunctivitis is initially conservative with simple cleaning, eye toilet and topical lubricants. It is important that patients are made aware of the contagious nature of viral conjunctivitis; for example, tissues used to wipe the eye must be discarded safely, and towels should not be shared. If symptoms persist, it is appropriate to consider ophthalmology review when a mild steroid (eg fluorometholone drops four times daily for four days) may be prescribed. Topical steroids should not be prescribed without a formal assessment at the slit lamp by the GP or ophthalmologist.

It is unknown how frequently otherwise asymptomatic cases may present with conjunctivitis as the only manifestation of SARS-CoV-2 infection, and it would be prudent in cases of suspected viral conjunctivitis to be additionally cautious during this pandemic. There is no specific treatment available for conjunctivitis caused by SARS-CoV-2. The main message is to be alert for the possibility of this representing a COVID-19 case and directing patients for testing and isolation per local guidelines.

For bacterial conjunctivitis, eye toilet will help, but it is likely a short course of a topical broad-spectrum antibiotic will also be required, such as chloramphenicol $1 \%$ drops four times daily or tobramycin $0.3 \%$ ointment three times daily for 4-7 days.

Table 2. Comparison between bacterial and viral conjunctivitis

\begin{tabular}{|c|c|c|}
\hline Characteristic & Bacterial & Viral \\
\hline Incubation period & 1-3 days & 3-7 days \\
\hline Patient age & $\begin{array}{l}\text { More prevalent in pre-school- } \\
\text { aged children and the elderly }\end{array}$ & All ages \\
\hline Duration & 3-4 days & Up to two weeks \\
\hline Laterality & Bilateral & Unilateral or sequential bilateral \\
\hline Vision & Usually good & $\begin{array}{l}\text { Usually good; can be reduced } \\
\text { by keratitis }\end{array}$ \\
\hline Systemic associations & Otitis media & Pharyngitis \\
\hline Discharge & Purulent or mucopurulent & Watery \\
\hline Cornea involvement & No & $\begin{array}{l}\text { Occasionally complicated by } \\
\text { keratitis }\end{array}$ \\
\hline Conjunctiva & $\begin{array}{l}\text { Papillae (red nodules, pale at } \\
\text { base) }\end{array}$ & $\begin{array}{l}\text { Follicles (pale nodules, red at } \\
\text { the base) }\end{array}$ \\
\hline $\begin{array}{l}\text { Pre-auricular } \\
\text { lymphadenopathy }\end{array}$ & No & Yes \\
\hline Causative organisms & $\begin{array}{l}\text { Staphylococcus epidermidis, } \\
\text { Haemophilus spp. and } \\
\text { Streptococcus spp. } .^{18}\end{array}$ & $\begin{array}{l}\text { Adenovirus spp., picornaviruses, } \\
\text { herpes viruses }\end{array}$ \\
\hline Contagious & Modestly contagious & Highly contagious \\
\hline
\end{tabular}

\section{Hygiene measures for patients with conjunctivitis}

The following tips should be recommended to patients: ${ }^{15}$

- Contact lens wear should be discontinued. When the condition has resolved, resume contact lens wear with fresh contact lenses.

- Use a clean towel or tissue each time you wipe your face and eyes. Discard tissues directly in a bin.

- Wash your hands very often. Always wash them before and after you eat, when you go to the bathroom, and after you sneeze or cough.

- Try not to touch your eyes. If you do, wash your hands immediately.

- Bacteria can live in makeup. Do not use eye makeup while your eyes are infected. Replace your makeup if

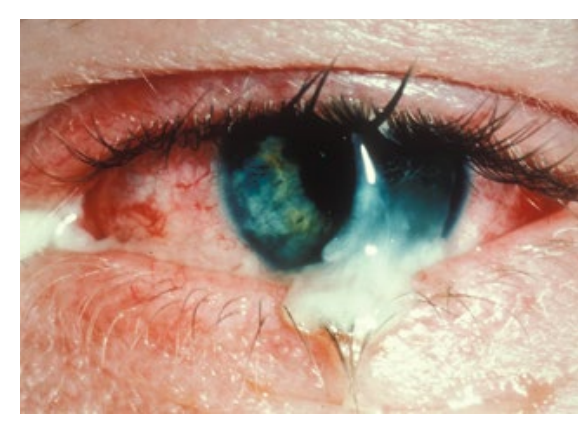

Figure 3. Bacterial conjunctivitis: injected bulbar conjunctival vessels and mucopurulent discharge overlying a normal cornea Image courtesy of Medical Photographic Imaging Centre, Royal Victorian Eye and Ear Hospital.

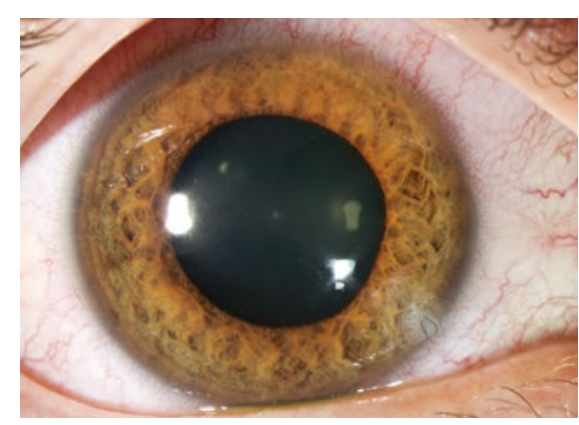

Figure 4. Circumciliary redness caused by dilated and congested perilimbal vessels in iritis Image courtesy of Jonathan Morris, Royal Perth Hospital, WA. 
you have an eye infection, and never share eye makeup with others.

- Make sure to wear and clean your contact lenses exactly as your optometrist or ophthalmologist recommends.

Initiating treatments - other conditions Less common conditions are often visually threatening, and GPs are recommended to consult with an ophthalmologist, initiate treatment if appropriate and arrange ophthalmology review. The Royal Australian and New Zealand College of Ophthalmologists (RANZCO) triage guidelines may assist in patient prioritisation. ${ }^{16}$

\section{Conclusion}

Although conjunctivitis does not appear to be a common associated feature of COVID-19 illness, there are some reports of conjunctival congestion occurring, and some reports of viral RNA presence in tears. Therefore, caution needs to be observed during the COVID-19 pandemic if the features align with a viral conjunctivitis. This article gives some tips for the diagnosis of red eyes to assist GPs to determine the most likely cause of redness so as not to risk missing more serious diagnoses as well as to avoid unnecessary contact with patients with suspected viral conjunctivitis. In areas with many COVID-19 cases, telemedicine rebates (set to expire 31 March 2021 at time of publication) will assist by enabling urgent definitive ophthalmology consultation and reducing patient travel, face-to-face appointments and unnecessary use of the national PPE stockpile.

\footnotetext{
Authors

Jane Khan MBBS, FRCOphth, FRANZCO, MD, Chair of Public Health Committee, The Royal Australian and New Zealand College of Ophthalmologists, NSW; Clinical Senior Lecturer, University of Western Australia, WA; Consultant Ophthalmologist, Royal Perth Hospital, WA

Heather G Mack PhD, FRANZCO, Clinical Associate Professor, Department of Surgery (Ophthalmology), University of Melbourne, Vic. hmack@eyesurgery.com.au

Competing interests: HGM reports personal fees from Novartis, where she is a member of the advisory board, regarding the launch of Luxturna ocular gene therapy in Australia.

Funding: None.

Provenance and peer review: Commissioned, externally peer reviewed.
}

\section{Acknowledgements}

The authors acknowledge the contributions of the Royal Australian and New Zealand College of Ophthalmologists Public Health committee, Fellows and staff.

\section{References}

1. Wu Z, McGoogan JM. Characteristics of and important lessons from the coronavirus disease 2019 (COVID-19) outbreak in China: Summary of a report of 72314 cases from the Chinese center for disease control and prevention. JAMA 2020;323(13):1239-42. doi: 10.1001/ jama.2020.2648.

2. Armstrong RA, Kane AD, Cook TM. Outcomes from intensive care in patients with COVID-19: A systematic review and meta-analysis of observational studies. Anaesthesia 2020. doi: 10.1111/anae.15201. [ePub ahead of print]

3. Seah I, Agrawal R. Can the coronavirus disease 2019 (COVID-19) affect the eyes? A review of coronaviruses and ocular implications in humans and animals. Ocul Immunol Inflamm 2020;28(2):1-5 doi: 10.1080/09273948.2020.1738501.

4. Loon SC, Teoh SCB, Oon LLE, et al. The severe acute respiratory syndrome coronavirus in tears. Br J Ophthalmol 2004;88(7):861-63. doi: 10.1136/ bjo.2003.035931.

5. van Doremalen N, Bushmaker T, Morris DH, et al. Aerosol and surface stability of SARSCoV-2 as compared with SARS-CoV-1. N Engl J Med 2020;382(16):1564-67. doi: 10.1056/ NEJMc2004973.

6. Xia J, Tong J, Liu M, Shen Y, Guo D. Evaluation of coronavirus in tears and conjunctival secretions

\section{Table 3. Treatments prescribed by ophthalmologists for conjunctivitis}

\begin{tabular}{lll}
\hline Condition & Cause & Treatment \\
\hline Viral conjunctivitis & $65 \%$ adenovirus & Supportive (cold compresses, eye toilet*) \\
& & Artificial tears, topical nonsteroidal treatment (eg ketorolac trometamol \\
& & $5 \mathrm{mg} / \mathrm{mL}$ ), topical steroid (eg fluorometholone three times daily for one \\
& & week) only after formal slit lamp examination
\end{tabular}

Acute bacterial conjunctivitis

\section{Staphylococcus aureus,} Staphylococcus epidermidis, Haemophilus influenzae, Streptococcus pneumoniae, Streptococcus viridans, Moraxella spp. ${ }^{17}$

Adult inclusion conjunctivitis Chlamydia trachomatis

Hyperacute bacterial Neisseria gonorrhoeae
conjunctivitis in adults or neonates

\begin{tabular}{lll}
\hline Herpes simplex keratitis & Herpes simplex virus & Topical acyclovir five times daily ${ }^{22}$ \\
\hline Allergic & Pollens, animal danders & Nonsteroidal anti-inflammatory (eg ketorolac trometamol 5 mg/mL) ${ }^{23}$ \\
& & Antihistamine (eg ketotifen $0.025 \%)^{18}$ \\
& Topical mast cell inhibitors (eg cromolyn sodium 4\%)
\end{tabular}

Topical chloramphenicol drops four times daily for one week $^{19}$

Tobramycin ointment three times daily for one week ${ }^{20}$ Azithromycin $1 \mathrm{~g}$ orally immediately ${ }^{21}$

Single-dose injectable cephalosporin

Also consider azithromycin $1 \mathrm{~g}$ orally in a single dose to treat concurrent chlamydia

*Eye toilet can be performed using a warm saline solution (1/2 teaspoon of table salt in one cup of slightly cooled boiled water). 
of patients with SARS-CoV-2 infection. J Med Virol 2020;92(6):589-94. doi: 10/1002/jmv.25725.

7. Colavita F, Lapa D, Carletti F, et al. SARS-CoV-2 isolation from ocular secretions of a patient with COVID-19 in Italy with prolonged viral RNA detection. Ann Int Med 2020;173(3):242-43. doi: 10.7326/M20-1176.

8. Jun IYJ, Anderson DE, Kang AEZ, et al. Assessing viral shedding and infectivity of tears in coronavirus disease 2019 (COVID-19) patients. Ophthalmology 2020;127(7):977-79. doi: 10.1016/j. ophtha.2020.03.026.

9. Scalinci SZ, Trovato Battagliola E. Conjunctivitis can be the only presenting sign and symptom of COVID-19. ID Cases 2020;20:e00774. doi: 10.1016/j.idcr.2020.e00774.

10. Ozturker ZK. Conjunctivitis as sole symptom of COVID-19: A case report and review of literature. Eur J Ophthalmol 2020;1120672120946287. doi: 10.1177/1120672120946287.

11. Romano MR, Montericcio A, Montalbano C, et al. Facing COVID-19 in ophthalmology department. Curr Eye Res 2020;45(6):653-58. doi: 10.1080/02713683.2020.1752737.

12. Kaufman HE. Adenovirus advances: New diagnostic and therapeutic options. Curr Opin Ophthalmol 2011;22(4):290-93. doi: 10.1097/ ICU.0b013e3283477cb5.
13. O'Brien TP, Jeng BH, McDonald M, Raizman MB. Acute conjunctivitis: Truth and misconceptions. Curr Med Res Opin 2009;25(8):1953-61. doi: 10.1185/03007990903038269.

14. Miller DD, Hasan SA, Simmons NL, Stewart MW. Recurrent corneal erosion: A comprehensive review. Clin Ophthalmol 2019;13:325-35. doi: 10.2147/OPTH.S157430.

15. Seewoodhary R, Stevens S. Transmission and control of infection in ophthalmic practice. Community Eye Health 1999;12(30):25-28

16. The Royal Australian and New Zealand College of Ophthalmologists. RANZCO triage guidelines for fellows and other health professionals. Surry Hills, NSW: RANZCO, 2020.

17. Lopez-Prats MJ, Marco ES, Hidalgo-Mora JJ, Garcia-Delpech S, Diaz-Llopis M. Bleeding follicular conjunctivitis due to influenza H1N1 virus. J Ophthalmol 2010;2010:423672. doi: 10.1155/2010/423672.

18. Azari AA, Barney NP. Conjunctivitis: A systematic review of diagnosis and treatment. JAMA 2013;310(16):1721-29. doi: 10.1001/ jama.2013.280318.

19. Feder HM Jr, Osier C, Maderazo EG. Chloramphenicol: A review of its use in clinical practice. Reviews Infect Dis 1981;3(3):479-91. doi: 10.1093/clinids/3.3.479.
20. Alves MRKJ. Evaluation of the clinical and microbiological efficacy of $0.3 \%$ ciprofloxacin drops and $0.3 \%$ tobramycin drops in the treatment of acute bacterial conjunctivitis. Rev Bras Oftalmol 1993;52:371-77.

21. Katusic D, Petricek I, Mandic Z, et al. Azithromycin vs doxycycline in the treatment of inclusion conjunctivitis. Am J Ophthamol 2003;135(4):447-51. doi: 10.1016/s00029394(02)02094-9.

22. Workowski KA, Berman S. Sexually transmitted diseases treatment guidelines, 2010. MMWR Recomm Rep 2010;59(RR-12):1-110.

23. Bielory BP, O’Brien TP, Bielory L. Management of seasonal allergic conjunctivitis: Guide to therapy. Acta Ophthalmol 2012;90(5):399-407. doi: 10.1111/j.1755-3768.2011.02272.x. 